\title{
SISTEMA PARA A PARTILHA DE INFORMAÇÃO TURÍSTICA EM PAÍSES DE EXPRESSÃO PORTUGUESA
}

\author{
SYSTEM TOWARDS THE TOURISTIC INFORMATION SHARING AMONGST \\ PORTUGUESE SPEAKING COUNTRIES
}

\author{
M. M. M. Moura - mmadeira@ualg.pt \\ Prof. a Doutora, CSI, FCT, Campus de Gambelas \\ Valter Lima - a14215@ualg.pt \\ Licenciado em Eng. de Sistemas e Informática, FCT, UALG \\ Júlio Mendes - jmendes@ualg.pt \\ Prof. Doutor, FEUA, Campus de Gambelas \\ Ana Leiria - aleiria@ualg.pt \\ Prof. a Doutora, CSI, FCT, Campus de Gambelas \\ João Albino Silva - jsilva@ualg.pt \\ Prof. Doutor, FEUA, Campus de Gambelas
}

\begin{abstract}
RESUMO
A comunicação eficiente e global foi sempre uma meta a atingir por parte dos destinos turísticos em expansão, de forma a potenciar um crescimento do sector e um desenvolvimento sustentável das regiões. Com o aparecimento das novas tecnologias da informação, a criação de redes de partilha de informação no sector turístico apoiadas tornou-se uma realidade e veio facilitar a implementação de acções e de programas de benchmarking entre os destinos turísticos envolvidos em projectos de cooperação. O desenvolvimento da Internet, como infra-estrutura pouco dispendiosa, permitiu finalmente quebrar muitas das barreiras de acesso que muitos destinos turísticos enfrentavam dada a falta de fundos de investimento nestas áreas. Os custos inerentes à concepção, instalação e manutenção de sistemas informáticos a funcionarem sobre a Internet passaram para uma fracção do custo de implementação inicial de um sistema tradicional, permitindo ainda uniformizar toda a tecnologia de comunicação utilizada. $\mathrm{O}$ artigo desenvolve a problemática da construção de uma rede de partilha de informação do sector turístico e propõe um modelo de desenvolvimento de um sistema de informação distribuído como infra-estrutura de suporte da rede. Desta forma, a exploração organizada de um fluxo de informação descentralizado permite a criação de sinergias entre os agentes envolvidos e, ao mesmo tempo, maximizar o desenvolvimento dos destinos turísticos emergentes. Uma tal rede para o desenvolvimento sustentável dos destinos turísticos dos países de expressão portuguesa torna possível o desenvolvimento de processos de melhoria contínua do desempenho global, processos esses orientados à persecução da competitividade, sustentabilidade e qualidade dos produtos turísticos.
\end{abstract}

Palavras-chave: Destinos Turísticos; Sistema da Informação; Sistema de Distribuição.

\section{INTRODUÇÃO}

A incorporação do turismo nas estratégias de desenvolvimento de um crescente número de países é uma das principais características do nosso tempo. 
A promoção do património cultural e natural tem tido, neste particular, a função de facilitar o aparecimento de mecanismos de dinamização das economias em crise ou em vias de desenvolvimento. Ao longo das últimas décadas, e que se prevê o seu aumento neste novo século, os agentes económicos privados e o sector público têm vindo a desenvolver um conjunto de acções que são o corolário do reconhecimento das possibilidades do turismo como instrumento de dinamização económica e de reestruturação de espaços urbanos e naturais em todos os continentes.

Esta relação entre espaços e o uso turístico, muitas vezes com um carácter conflituante e não isenta de problemas, justifica e aconselha a consideração dos seguintes aspectos:

- Em primeiro lugar, o da garantia da competitividade turística dos países e regiões. Dependendo esta da qualidade da organização dos territórios, em particular em domínios como o do desenvolvimento sustentável, o ordenamento espacial e urbanístico, e o da adequada funcionalidade em infra-estruturas, acessibilidades e equipamentos;

- Em segundo lugar, o do planeamento estratégico integrado na gestão de centros históricos e/ou parques naturais;

- E, por último, o da coordenação institucional num contexto de crescente complexidade administrativa, capaz de articular o ordenamento e o planeamento à operacionalização de sistemas de gestão e ao partenariado entre o sector público e o sector privado.

No caso dos países que fazem parte da Comunidade de Países de Língua Portuguesa (CPLP), este esforço de defesa de um património cultural e natural tão rico e diversificado e a sua ligação às actividades turísticas, poderá ser aprofundada com uma adequada articulada entre todos estes países que partilham, não só a mesma língua, mas igualmente uma vontade de cooperação e partenariado. Neste contexto, que papel podem desempenhar as tecnologias de informação e de comunicação (TICs) neste contexto? "O mundo de hoje está profundamente marcado pela revolução das tecnologias de informação e comunicação [...] Nesta era da informação, é a capacidade de utilizar eficientemente as tecnologias de informação e comunicação que, cada vez mais, determina a competitividade e relevância de um país na economia global", conforme referido na Declaração de Missão da Política de Informática, aprovada pela Resolução N28/2000, de 12 de Dezembro, do Conselho de Ministros da República de Moçambique (COMISSÃO PARA A POLÍTICA DE INFORMÁTICA, 2002). O mesmo facto é reconhecido no documento "Nova Parceria para o Desenvolvimento de África" (NEPAD, 2001), destacando como sector prioritário a diminuição do fosso digital pelo investimento nas Tecnologias de Informação e Comunicação (TICs); no mesmo documento, para a mobilização de recursos, o sector do turismo é identificado como uma oportunidade de acesso a mercados capazes de gerar importantes receitas, de funcionar como factor promotor da integração económica e de dinamizar o aproveitamento de recursos naturais africanos tais como o turismo cultural, o ecoturismo e o turismo de aventura.

Acreditamos que para a sustentação do sector do turismo e a avaliação do desempenho das suas diversas actividades, é necessário lidar com possíveis constrangimentos com especial atenção aos de natureza organizativa e estrutural. É neste contexto que a construção de uma rede de partilha de informação no sector turístico se revela como um elemento fundamental de valorização. A utilização das novas tecnologias da informação e comunicação no suporte da rede de partilha de informação permite apoiar a constituição e funcionamento da rede e abstrair a localização geográfica, diversidade, complexidade e volume dos dados da actividade. Desta forma, explorando a capacidade agregadora e de uniformização das tecnologias de informação, é possível a utilização da rede como um meio de partilha de informação, de difusão de "boas práticas" propiciando o estabelecimento de alianças estratégicas de cooperação empresarial informal e fomentando relações inter-organizacionais de aproximação ao mercado.

Enc. Bibli: R. Eletr. Bibliotecon. Ci. Inf., Florianópolis, n. esp., 2º sem. 2008 
O objecto desta comunicação é a apresentação de uma proposta da aplicação das TICs na criação e utilização de uma rede de partilha de informação no sector turístico. Nesta proposta, mais do que apontar uma solução traça-se uma abordagem e apresenta-se um modelo de um sistema de informação que suporte a rede de partilha. Na sequência desta introdução, esta comunicação inclui uma descrição do enquadramento, os conceitos de rede de partilha de informação turística e de sistemas de informação e bases de dados distribuídos, a concepção e desenvolvimento da rede de partilha de informação e do sistema de apoio à rede e perspectiva a exploração inicial e o alargamento da rede, salientando subprodutos da rede apoiada em TICs.

\section{ENQUADRAMENTO}

A aplicação das TICs na gestão integrada do sector turístico apresenta duas vertentes. A escolha das tecnologias a aplicar depende do modelo de gestão adoptado, do volume e estrutura da informação a tratar; o modelo de gestão adoptado depende da análise das oportunidades e ameaças a enfrentar bem como das opções tomadas na abordagem à complexidade da actividade a gerir.

A globalização implica que as oportunidades e ameaças, parceiros e concorrência possam estar geograficamente distanciados mas, ainda assim, mantenham actividades muito próximas e fortemente relacionadas. Outra consequência da globalização é a volatilidade dos mercados, parcialmente determinados pela pressão global na oferta e procura. Como a própria actividade pode desgastar o produto, a perenidade passa pelo zelo do produto oferecido.

No turismo, como em outras actividades económicas, podem identificar-se como vantagens competitivas o menor custo e a qualidade. O menor custo depende da melhoria da produtividade dos factores e do funcionamento dos mercados. A qualidade de um produto, distinguindo-o dos seus competidores, sustenta a actividade. Para além dos aspectos relacionados com a qualidade dos produtos turísticos importa tomar em consideração questões relacionadas com a sustentabilidade e com a problemática da competitividade dos destinos turísticos, sempre que se considera a questão da gestão integrada dos mesmos.

A dificuldade de aplicação das TICs na gestão integrada dos destinos turísticos e nas redes que estabelecem entre si decorre da complexidade que o fenómeno da globalização veio provocar nas actividades do sector e, de futuro, não se antevê outra possibilidade que não o recurso, cada vez mais intensivo, a essas mesmas tecnologias.

Em qualquer sistema de informação, os requisitos são determinados pelo utilizador e cabe ao informático a concepção de uma solução que inclua a melhor tecnologia para o caso de aplicação. Considerando que o sistema de informação alvo visa apoiar a criação e utilização da rede de partilha de informação, a sua concepção pode e deve acompanhar o desenvolvimento da rede.

Existem alguns métodos e técnicas desenvolvidas para redes de partilha de informação turística (AFFIT) e avaliação do desempenho de destinos turísticos (MENDES, 2004) que permitem uma panorâmica do caso presente. Mas a especificidade de cada país, dos seus organismos de tutela, da regulamentação em vigor, das infra-estruturas e recursos existentes e a forma como os diversos elementos se organizam impede a criação de um modelo único. Assim, desenvolveu-se um modelo de informação que possa acompanhar a implementação e evolução da rede de partilha de informação.

Sugere-se que, no desenvolvimento do sistema de informação para o apoio à rede de partilha de informação turística seja usado software de código aberto, com Licença Pública Geral. Como se lê em http://www.debian.org/intro/free.pt.html, essas licenças permitem a instalação do software em quantas máquinas se pretenda, sem restrições ao número de utilizadores, sendo autorizada a cópia do software e a sua distribuição, não havendo restrições na modificação do software (excepto a manutenção de algumas notas intactas) e não havendo

Enc. Bibli: R. Eletr. Bibliotecon. Ci. Inf., Florianópolis, n. esp., 2º sem. 2008 
restrições sobre a distribuição ou mesmo sobre a venda do software. Sobre a qualidade e maturidade do software de código aberto, cite-se (UNIÃO EUROPEIA, 2000, p.23), que sugere aos estados membros, entre outras premissas, a legislação no sentido de privilegiar soluções de código aberto em concursos públicos.

A utilização da língua portuguesa facilita a comunicação entre os organismos colaborantes, a partilha de informação turística, a utilização do sistema informático e a formação dos utilizadores (Figura 1). São várias as distribuições de software que suportam a utilização da língua portuguesa de forma nativa.

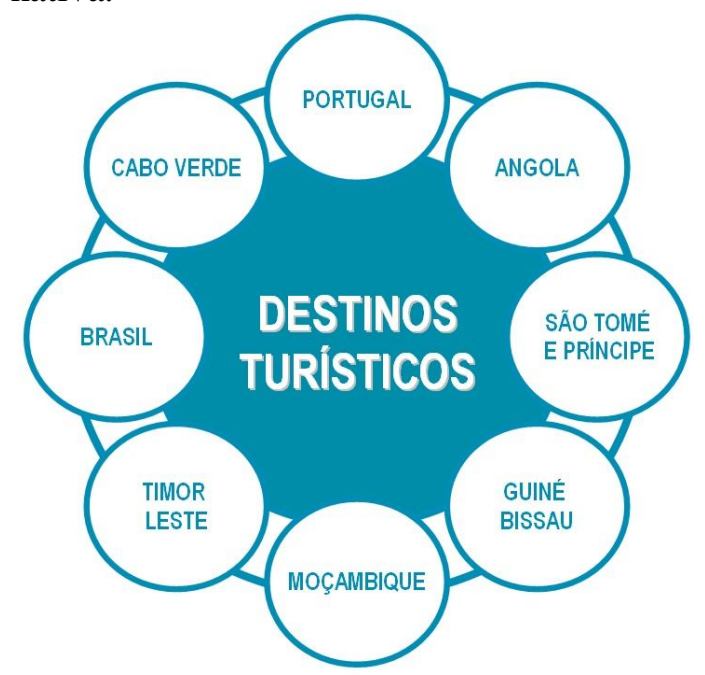

Figura 1 - Parceiros na rede de partilha de informação.

$\mathrm{Na}$ sequência do presente enquadramento, revêem-se agora os conceitos fundamentais de redes de partilha de informação no sector turístico e das redes informáticas e sistemas distribuídos, alvo da presente proposta de integração.

\section{CONCEITOS}

\subsection{Rede de partilha de informação turística}

O desenvolvimento de processos de melhoria contínua do desempenho global dos destinos turísticos procura, acima de tudo, reorientar o conjunto da actividade turística para a adopção de novos paradigmas de gestão assentes numa cultura de relações em cadeia, norteada por princípios de sustentabilidade, de qualidade e de excelência empresarial. O clima de cooperação e de colaboração entre os diversos actores reveste-se de uma importância crucial para a sustentação de uma visão global do produto turístico.

Numa perspectiva de gestão integrada, o que se requer é um desenvolvimento equilibrado de comportamentos, atitudes, equipamentos e outras infra-estruturas necessárias para satisfazer as exigências dos consumidores e dos stakeholders envolvidos na prestação de serviços do sector. Ao mesmo tempo, coloca-se uma ênfase crescente na sustentabilidade de tal desenvolvimento, de modo a que o turismo não comprometa os recursos naturais e culturais de um país.

Ao nível do processo de avaliação do desempenho verifica-se a necessidade de monitorizar todos os aspectos que tenham a ver com a problemática da qualidade dos produtos turísticos, assim como os impactes nos visitantes, nas organizações, no ambiente e na comunidade local. A competitividade dos destinos turísticos e a imagem dos países e das regiões enquanto destinos turísticos, assim como a qualidade dos serviços prestados depende essencialmente da capacidade criativa das pessoas, da sua habilidade para introduzir novas tecnologias, o uso de novos processos e formas organizativas (SANCHO, 1993). 
O desempenho do destino turístico é maximizado quando baseado na partilha de conhecimentos e numa cultura de aprendizagem contínua e de inovação. Maximizar os fluxos de informação para todo os que estão envolvidos é essencial para a consolidação deste processo de aprendizagem dos actores envolvidos (KLEIN, 2000; EFQM, 1999).

Neste contexto, o estabelecimento de parcerias, especialmente entre os sectores público e privado, constitui uma das fórmulas mais eficazes para o desenvolvimento de lugares turísticos e para a exploração de recursos locais, assim como a chave para a capacidade dos destinos oferecerem produtos com qualidade (BUHALIS, 2000; LEONI, 1999; MANENTE e FURLAN, 1998; RITCHIE e CROUCH, 1997; WANHILL, 1995).

Uma das possibilidades de fomentar e de institucionalizar formas de cooperação entre os actores seria através da criação de uma rede holónica ${ }^{1}$. O conceito, introduzido por McHugh et al. (1995), pretende traduzir uma nova forma de estar e de reagir das organizações, assente no estabelecimento de plataformas de comunicação, troca de informação e de resposta eficaz às solicitações do mercado. Esta nova concepção de funcionamento em cadeia de prestação assente num processo de reengenharia dos negócios, tendo sempre como preocupação central a satisfação dos clientes e o sucesso das organizações num ambiente competitivo, tem sido aplicada com sucesso no contexto dos destinos turísticos e vem ao encontro do que se pretende pôr em evidência quando se procura operacionalizar a questão da cooperação entre os actores, organizações e demais entidades regionais

O cliente é sempre o ponto fulcral do sistema holónico. A rede de organizações holónicas partilha objectivos comuns e utiliza a qualidade total, bem como outras técnicas de gestão, para que todos os participantes trabalhem em direcção ao mais alto nível de satisfação dos clientes (MCHUGH et al., 1995).

A rede holónica pode ser descrita como um conjunto de organizações que actuam de uma forma integrada e se encontram ligadas em termos orgânicos ${ }^{2}$. Cada organização, com as suas aptidões específicas é designada por holon. No caso do turismo, e através da combinação de competências, a rede assume uma determinada configuração, designada por organização virtual, destinada a gerir cada oportunidade de negócio detectada no mercado e, assim, contribuir para melhorar o desempenho e a prestação de cada organização do destino turístico. Em termos mais gerais, o conceito fundamental associado a uma rede de partilha de informação é a criação de uma rede de contactos entre os vários intervenientes para a partilha de conhecimentos, experiências e práticas e para a disseminação (electrónica ou pessoal) de informação, de maneira a desenvolver formas efectivas de comparação para melhorar a competitividade, a sustentabilidade e a qualidade de actividades e produtos.

Os objectivos últimos da rede de partilha de informação são:

- Promoção e desenvolvimento de um sistema interactivo dinâmico e em constante evolução entre os agentes, públicos ou privados, envolvidos no sector turístico.

- Ajudar os vários intervenientes a planear e gerir as suas actividades de forma coordenada e eficiente.

- Desenvolver um sistema de comparação (benchmarking).

- Promover a colaboração e desenvolvimento de parcerias entre os actores.

- Desenvolver boas práticas e linhas de acção para a gestão integrada da qualidade.

- Fornecer apoio e gerir a partilha de informação com outras instituições.

Uma rede de partilha de informação considera diferentes níveis de participação.

\footnotetext{
1 A designação da rede tem origem na palavra que deriva do grego holon e que significa conjunto, parte de dentro. Cada holon deve ser entendido como um nó da rede ou um negócio, no entender dos autores.

2 Como características da rede referem-se as seguintes: a rede não é organizada hierarquicamente; cada negócio ou holon tem as características da rede inteira e é igual aos outros; a rede está num equilíbrio dinâmico; a rede é auto-regulada; o acesso e a troca de informação através da rede estão abertos; a rede é evolutiva e está em constante interacção como o meio; é uma rede de conhecimento e de auto aprendizagem
} 
A participação plena destina-se aos agentes fundadores, públicos ou privados, e independentemente do seu campo de actuação.

A participação restrita destina-se a colaboradores com os quais se mantêm relações privilegiadas, sejam organismos, associações ou outras redes.

A viagem turística nunca é um produto simples. É feita de componentes oferecidos por uma variedade de organizações, com diferentes objectivos e estruturas de funcionamento. Os fornecedores do serviço devem reconhecer que a satisfação do visitante com a sua organização é influenciada por vários serviços que o precedem e por serviços que se lhe seguem. O sucesso do produto-destino é a prestação da combinação certa de componentes para satisfazer as exigências do visitante, o que requer coordenação, cooperação e parcerias. Do ponto de vista da gestão, é claro que a organização não controla muito dos factores que contribuem para uma experiência de qualidade no destino turístico. Por outro lado, as capacidades e possibilidades dos actores e dos operadores controlarem estes factores são diversas e distintas; alguns são controlados por umas organizações, outros são controlados por outros e outros factores, ainda, não são controlados por ninguém. Pode, assim, acontecer que os padrões prometidos ou sugeridos nas campanhas de comunicação institucionais não vão ao encontro da realidade das experiências dos visitantes durante a sua estada.

Uma das funções das políticas de turismo ao nível do destino é tentar reconciliar os interesses divergentes dos diferentes actores, dinamizar a cooperação entre as partes interessadas e, simultaneamente, tentar trabalhar em harmonia com o plano nacional de turismo (SILVA et al., 2001; DAVIDSON e MAITLAND, 1997; O’NEILL et al., 1994).

As parcerias, protocolos e outras formas institucionais de colaboração e de cooperação entre as organizações do destino turístico são tanto mais necessários quantos se reconhecem que a prossecução de objectivos apenas é possível com o empenhamento e a participação de todos os actores e organizações do destino.

\subsection{Redes informáticas e Sistemas distribuídos}

A necessidade de um desenvolvimento sustentável das regiões turísticas assim como a persecução na melhoria da gestão dos destinos turísticos levou a que, cada vez mais, os operadores sentissem a necessidade de comunicar entre si de forma a gerir melhor o fluxo de turistas em cada região, tentando determinar o desempenho de cada destino, incluindo a melhoria da capacidade das suas infra-estruturas.

Assim, a disponibilização de uma grande quantidade de informação permite a cada operador analisar a sua posição face à dos seus parceiros assim como determinar quais os factores que influenciam o desempenho de cada região.

Até a data, os custos inerentes à implementação de um sistema de análise global bem como a gestão das infra-estruturas das redes e as frequentes falhas de comunicação tem sido uma barreira ao seu desenvolvimento. O disseminar da Internet como veículo de transporte de informação privada tem permitido, cada vez mais, a redução significativa dos custos de comunicação e de gestão da informação disponível localmente.

\subsubsection{Rede informática}

Qualquer sistema que esteja ligado através de um nó a outros sistemas similares e descentralizados é considerado parte integrante de uma rede. As redes informáticas foram desenvolvidas de forma a promover a troca de informação descentralizada entre diversos nós dispersos geograficamente. A vantagem é que não existe nenhum nó que dependa directamente dos nós adjacentes, reduzindo as possíveis falhas de comunicação e o impacto dessas falhas nos demais nós.

As redes podem classificar-se em diversas categorias. Se por um lado existem redes de alcance local ou regional que permitem a comunicação e troca de informações numa área restrita geograficamente (chamadas de LAN - Local Area Network e WAN - Wide Area 
Network) e que, normalmente, são de carácter privado, existem redes de alcance globais que interligam regiões, países e continentes. A rede de alcance mundial mais conhecida actualmente é a Internet e que se caracteriza pela interligação de inúmeras redes privadas e públicas. A sua grande vantagem é o alcance global, o acesso público.

Até há muito pouco tempo atrás, as redes privadas continuavam a coexistir com a Internet pelo simples facto de que não se podia garantir a comunicação segura entre entre dois ou mais pontos interligados através da utilização de uma rede de acesso geral. Hoje em dia com a disseminação e melhoria dos sistemas de Virtual Private Networks - VPN's, certificados digitais e comunicações encriptadas, já é possível estabelecer ligações dedicadas e seguras através de da World Wide Web beneficiando de infra-estruturas já existentes e consequentemente reduzindo os custos de ligação. Este factor tem permitido que organizações e operadores europeus troquem informações entre si, auferindo de estatísticas referentes à performance dos destinos turísticos correspondentes.

Mais recentemente tem-se assistido ao interesse na utilização de redes em grande-escala ( grid) para a constituição de sistemas distribuídos. O desenvolvimento das tecnologias grid visa a utilização internacional das infra-estruturas de rede, obedecendo a elevados padrões de qualidade e disponibilidade. Desta forma, os utilizadores podem usufruir de aplicações distribuídas sobre sistemas de elevada capacidade, com meios que permitem a resolução de problemas complexos com elevados requisitos computacionais.

\subsubsection{Sistemas distribuídos}

Um sistema distribuído é aquele cujos componentes, localizados em computadores ligados a uma rede, comunicam e coordenam as suas acções apenas pela troca de mensagens (COULOURIS et al., 2001). A motivação subjacente aos sistemas distribuídos é a partilha de recursos, que incluem não só dispositivos (como modems) e periféricos (como impressoras ou scanners) como também capacidade de processamento ou armazenamento de dados.

Num sistema distribuído pode-se distinguir o nível das aplicações, a camada intermédia de serviços de comunicação e partilha de recursos (middleware) e a camada de comunicação propriamente dita, que é normalmente a Internet.

Os principais desafios dos sistemas distribuídos, desde a sua criação, incluem a heterogeneidade (de equipamentos, de software e componentes), abertura, segurança, escalabilidade, gestão de falhas, concorrência e transparência (COULOURIS et al., 2001).

A heterogeneidade advém da utilização de máquinas e dispositivos de diferentes construtores, utilizando vários sistemas operativos e diferentes conjuntos de aplicações. A abertura de um sistema condiciona a forma de um sistema computacional ser estendido ou re-implementado; a abertura está fortemente associada ao acesso à documentação sobre os serviços de partilha de recursos. O conceito de segurança da informação inclui os aspectos de confidencialidade, integridade e disponibilidade. A escalabilidade de um sistema é determinada pela capacidade de um sistema manter a eficiência operacional perante um aumento significativo de recursos e utilizadores. A gestão de falhas visa as situações que possam produzir resultados incorrectos ou a paragem do sistema e inclui a detecção, tolerância e recuperação de falhas. A gestão da concorrência incide sobre múltiplos acessos a dados e a recursos. Um sistema é dito transparente se a normal utilização não obriga que sejam conhecidos detalhes da implementação.

Estas características dos sistemas distribuídos são muito importantes no sucesso da utilização das tecnologias de informação e comunicação em diversas actividades.

Independentemente do modelo utilizado (master-slave, client-server ou peer-to-peer), as aplicações distribuídas na Internet são cada vez mais abundantes (como banca electrónica ou para a partilha de áudio ou vídeo). 
Com a proliferação de dispositivos miniaturizados e de redes sem fios, tem-se assistido à progressiva integração de dispositivos computacionais pequenos e portáteis em sistemas distribuídos. Os dispositivos a que aqui nos referimos incluem computadores portáteis, agendas digitais (Personal Digital Assistant (PDA)), smartphones, e câmaras digitais. A exploração da capacidade computacional destes dispositivos, aliada à portabilidade e versatilidade de formas de ligação a diferentes redes é designada por computação móvel. Este é outro aspecto do sistema que se pode mostrar útil na divulgação de conteúdos sobre produtos turísticos, ainda que em locais mais remotos.

\section{CONSTITUIÇÃO DE UMA REDE DE PARTILHA DE INFORMAÇÃO}

No sector do turismo, o uso das TICs como forma de aumentar o desempenho, quer em termos de competitividade ou quota de mercado varia com a maturidade de utilização dessas tecnologias (JEONG et al., 2002). Neste contexto, é de salientar que o sucesso da integração das TICs está associado às práticas de gestão e a variáveis organizacionais como dimensão, estrutura ou cultura e a capacidade de assimilar as novas formas de gestão de informação e delas tirar partido.

Alguns autores (XIANG et al., 2002) defendem uma sequência de etapas pelas quais as organizações turísticas passam na adaptação à utilização das TICs: numa fase inicial, aplicações sobre a Internet são usadas em vez de formas mais tradicionais de operação (por ex., portais em vez de brochuras); numa etapa mais evoluída, tecnologias mais avançadas como bases de dados; apenas numa terceira fase, existe a exploração efectiva da tecnologia ao serviço da informação, comunicação e colaboração (comunidades $\mathrm{B} 2 \mathrm{~B}$, ou redes de partilha de informação).

\subsection{Planeamento}

A presente comunicação visa a constituição de uma rede de partilha de informação para os países de expressão portuguesa, concretizando o modelo de suporte à informação de qualidade.

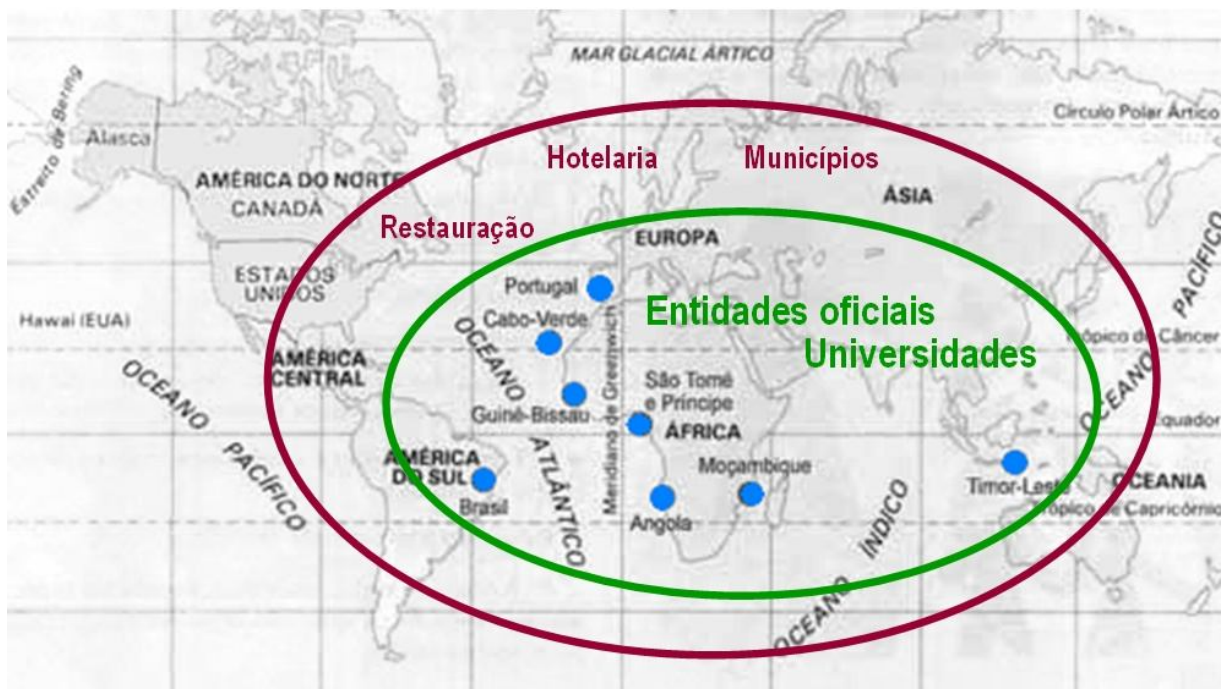

Figura 2 - Implementação da rede

(fonte: http://www.exercito.gov.br/03Brafor/operacoes/felino/cplp/cplp.htm)

Esta proposta considera três fases, temporalmente sobrepostas: 
A - Estabelecimento de protocolos de colaboração de forma a reunir, a nível governamental, os grandes parceiros institucionais - os países da CPLP (Figura 2).

Nesta fase, seria interessante reunir as organizações nacionais de turismo, de informática, institutos de estatística.

Do ponto de vista do sistema de informação prevê-se nesta fase:

- a criação de uma base de dados dos organismos e seus contactos;

- a criação de uma base de dados de documentos (ou apontadores para os documentos), que pode incluir regulamentação legal, concursos de bolsas ou programas de dinamização da área, resultados de conferências multinacionais;

- a versão electrónica de um diário de notícias ou semanário;

- um fórum de discussão entre as entidades colaborantes e de apoio à fase seguinte.

B - Alargamento da rede a parceiros académicos e instituições transnacionais.

Nesta fase, seria interessante estruturar a gestão do desempenho na actividade turística, identificando métodos e técnicas aplicáveis ao conjunto dos agentes e planear o sistema de informação que apoie a utilização desses métodos e técnicas e a produção de indicadores. Para além das organizações governamentais dos diferentes países, a rede é alargada a agentes e operadores do sector turístico.

É neste âmbito que se situa uma das principais contribuições da presente comunicação: um sistema que permite estruturar, de forma dinâmica, a gestão da qualidade de destinos turísticos e instrumentalizar a gestão corrente do desempenho na actividade turística.

A título exemplificativo, alguns indicadores da vertente ambiental da gestão de zonas costeiras (SILVA, et al., 2001) poderiam reflectir a qualidade da água em zonas balneares, a qualidade das praias e marinas ou a qualidade das águas interiores superficiais. A definição de que indicadores usar e de que forma cada um deve ser entendido e calculado poderão ser objecto de discussão. Em cada país, o estudo destes indicadores e a continuidade da sua utilização implicam o inventário dos recursos abrangidos, as instituições com informação necessária à produção dos indicadores e a forma e periodicidade de obtenção dessa informação, a articulação dos vários dados recolhidos e a sua ponderação no cálculo final.

Do ponto de vista do sistema de informação, nesta fase é necessário acrescentar uma base de dados de natureza estatística. A questão fulcral, nesta fase, não é a natureza dos dados ou o seu tratamento, mas a quantidade de informação e qualidade do tratamento dessa informação. Em cada país as fontes de dados serão particulares, como o serão também os mecanismos de recolha e armazenamento dessa informação.

A operacionalização dos indicadores de qualidade da vertente ambiental de um destino turístico litoral foi demonstrada no sistema piloto de informação criado na Universidade do Algarve, para servir de base à partilha de informação. A replicação desse sistema, em cada um dos países, acompanhada da formação em TICs e consultoria em técnicas de gestão de desempenho do sector turístico, permitirão a transferência de know-how, dotando cada um dos parceiros de capacidade operacional de gestão dos seus recursos permitindo também a cooperação entre os vários subsistemas.

É de notar que uma rede de partilha de informação não serve o seu propósito se for um conjunto de redes satélites. É fundamental a organização de dados de forma distribuída para a cooperação entre os parceiros.

Consoante os indicadores, aplicações distribuídas na Internet segundo um modelo clientserver ou peer-to-peer, escondem a distribuição geográfica do sistema, sendo transparentes para o utilizador. Outras questões a acautelar nesta fase incluem a segurança da informação, a gestão de falhas e a escalabilidade.

Enc. Bibli: R. Eletr. Bibliotecon. Ci. Inf., Florianópolis, n. esp., 2º sem. 2008 
C - Propagação da rede de partilha de informação a nível regional

Nesta fase, e após estar consolidada a rede de partilha de informação, propõe-se o seu alargamento a nível regional. Esta etapa considera que cada país deve ir integrando as suas províncias, regiões ou estados com uma abordagem semelhante à seguida na fase B. A integração e actualização das TICs empregues na rede de partilha de informação é simplificada pelo facto de existir uma estrutura de ensaio e transferência de conhecimento. Nesta fase, para além de benchmarking e troca de experiências e boas práticas, pode esperarse algumas inovações como a inclusão de informação multimédia para divulgação dos produtos ou formação dos agentes ou mesmo o desenvolvimento de soluções móveis.

\subsection{Visão integrada do sistema de informação}

A missão agregadora do Sistema de Informação é conseguida pela articulação de vários componentes que servem os objectivos da rede:

- um portal de acesso aos participantes e visitantes;

- um fórum de intercâmbio perguntas/respostas;

- uma base de dados para suporte documental de seminários, estudos e projectos desenvolvidos e respectivas conclusões;

- uma base de dados de natureza geral, com informação comercial ou publicitária que permita a criação e a actualização dinâmica do portal;

- uma base de dados de natureza estatística, que suporte a recolha e tratamento da informação necessária à avaliação do desempenho do destino turístico.

O ponto de acesso ao Sistema de Informação consiste num portal, com zonas de acesso público ou restrito, consoante a participação (plena ou restrita) na Rede.

A zona de acesso público poderá incluir informação geral sobre o sector turístico e informação personalizável sobre empresas e instituições intervenientes e a publicação, de forma gráfica e apelativa dos indicadores de desempenho - competitividade, sustentabilidade e qualidade - do destino turístico. Desta forma, todos os agentes intervenientes poderão marcar presença na Internet, divulgando e promovendo a sua actividade. As zonas de acesso restrito permitiriam aceder ao fórum de intercâmbio e às três bases de dados, para consulta ou inserção/actualização de informação.

Uma das funcionalidades do sistema consiste num fórum de intercâmbio entre os diferentes actores. Cada actor poderia definir os seus domínios de interesse, sendo notificado automaticamente de quaisquer novidades nos campos seleccionados.

Outra funcionalidade do sistema reside na existência de uma base de dados para suporte documental dos seminários e reuniões dos agentes da Rede, bem como arquivo documental de estudos e projectos. Esta funcionalidade permite a troca de conhecimentos e boas práticas, fundamental para a cooperação dos diversos actores. Naturalmente, pela natureza delicada de tal informação, o acesso deve poder ser definido para cada caso e revisto pelos autores do documento.

É conveniente que seja incluída uma base de dados de natureza geral, com informação comercial ou publicitária que permita a criação e a actualização dinâmica do portal. Esta base de dados permitirá também o registo e a associação dos utilizadores às instituições, fundamental para a gestão de acessos. Por exemplo, a um empregado de uma instituição poderá ser atribuída permissão de consulta de dados durante determinado período de tempo, correspondente ao contrato de trabalho; outro empregado da mesma instituição poderá ser responsável pela actualização dos elementos de desempenho - competitividade, sustentabilidade e qualidade - dessa instituição na base de dados estatísticos. Parte da informação desta base de dados poderá ser de acesso restrito, reflectindo parcerias e facilitando acções concertadas. 
A gestão da base de dados de natureza estatística, para suporte da recolha e tratamento da informação necessária à avaliação do desempenho do destino turístico assume um carácter particular e mais sensível.

O carácter particular deve-se à articulação entre população alvo, dimensão das amostras, período e método de implementação. Assim, a modelação da base de dados para considerar as diversas origens dos dados a manter, as diferentes periodicidade e método de obtenção deve ser objecto de especial atenção bem como os procedimentos de extracção de informação.

É importante salientar dois pontos-chave que o presente sistema endereça: a natureza privilegiada da informação base (por exemplo, o desempenho de serviço de uma instituição específica) e ao impacto negativo de informação inexacta/desactualizada.

A extracção dos indicadores de desempenho - competitividade, sustentabilidade e qualidade não deve ser considerada um procedimento estático, algo que, uma vez feito, poderá ser aplicado novamente em períodos posteriores, devendo a ponderação dos diversos factores ser devidamente monitorizada.

É conveniente que seja mantido um processo de análise sobre todo o processo, não só para garantir a qualidade/idoneidade dos elementos obtidos, como também para identificar atempadamente quaisquer anomalias. Como exemplo, as perguntas das entrevistas e a representatividade dos indivíduos que compõem as amostras são particularmente susceptíveis a erro.

Para prevenir a disseminação de informação desactualizada e garantir a possibilidade de correcção, é conveniente que seja controlada a posterior utilização da informação gerada, quer seja incorporada em páginas das empresas e instituições da Rede, quer seja reflectida por outras instituições externas.

\subsection{Particularidades}

A implementação da Rede de Informação implica várias vertentes: uma ligada à organização e métodos de trabalho dos diferentes actores; outra associada ao sistema de informação que apoia a Rede; outra respeitante ao treino de competências nas TIC de elementos dos diversos parceiros de forma a manter uma atitude pró-activa na geração de informação a ser partilhada pela rede.

Se por parte das entidades gestoras não houver cultura de gestão de desempenho, a utilidade do presente sistema fica hipotecada. Se por parte dos técnicos que apoiam a rede, não houver uma cultura de serviço dinâmica, visando a manutenção e evolução do sistema de informação visando a automação e simplificação dos procedimentos, a utilidade do sistema será ultrapassada pelo custo de manutenção.

Do ponto de vista das organizações, a constituição da Rede implica o envolvimento de todos os agentes, que devem contribuir para a produção e utilização da informação.

Do ponto de vista do sistema de informação, há que separar as fases de desenvolvimento e teste das fases subsequentes de exploração e manutenção do sistema. $\mathrm{O}$ custo das diferentes fases implica necessariamente uma análise informática dos diferentes componentes. No entanto, é possível adiantar que esse custo reflectirá o nível tecnológico informático dos intervenientes (formados ou a formar), quer a nível de pessoal quer a nível dos equipamentos e aplicações informáticas envolvidas.

Alguns cuidados na definição inicial do sistema informático podem minorar os custos globais. Um dos desafios do desenvolvimento deste tipo de aplicações é a comunicação com o utilizador. O portal de suporte a este sistema em particular deverá ser acedido por indivíduos com diversos perfis, culturas e objectivos, e deve ser cuidadosamente estudado para garantir o interesse e a confiança dos parceiros e utilizadores do sistema.

É fundamental que um produto desta natureza seja de fácil acesso e não envolva grandes períodos de espera. A manutenção destas características torna-se mais problemática quando se 
considera a discrepância entre as características das redes de telecomunicações dos vários destinos turísticos envolvidos. É por isso necessário manter a simplicidade do site, sem perder a clareza e a facilidade de acesso às diversas funcionalidades, não descurando, no entanto o carácter apelativo que um produto moderno desta natureza tem que apresentar.

O desafio é tanto maior se se considerar a quantidade e diversidade de informação e acções a que o portal deve dar acesso. A clareza dos conteúdos e dos caminhos condiciona fortemente a facilidade de utilização do produto e garantem o interesse dos potenciais utilizadores do site. Deste modo pretende-se desenvolver um produto multimédia, interactivo e essencialmente de acesso não linear, que tanto quanto possível, não envolva tempos de espera indesejáveis.

Note-se que, por exemplo, da página de rosto devem sair acessos para vários tipos de utilizadores, com diferentes permissões de acesso, e com diferentes objectivos, que devem estar cientes da utilidade do caminho que pretendem percorrer desde o início. É um problema de engenharia de software que será necessário estudar, implementar e validar.

O portal deverá também estar dotado de mecanismos de ajuda, incluindo tutoriais de apoio a diversas acções, incluindo a consulta de informação e a introdução de dados nas bases de dados. Dependendo dos objectivos dos tutoriais, estes devem poder ser acedidos de qualquer local ou apenas das páginas a que dizem respeito.

Uma outra preocupação fundamental no desenvolvimento da ferramenta informática de apoio ao projecto é a segurança. A confiança dos vários utilizadores no produto, e por consequência a capacidade de manter o projecto, depende do sistema de segurança a implementar. Nesse sentido, é preciso identificar cada utilizador, validar essa identificação e associar sempre que necessário um utilizador a um nome de utilizador, a uma palavra passe e a um conjunto de permissões. O desenvolvimento do sistema de segurança deve contemplar a solidez da palavra passe, a protecção de documentos, texto, imagens ou vídeos confidenciais ou de carácter reservado e naturalmente a capacidade de proteger as bases de dados.

A determinação inequívoca de quem tem acesso a que informação, é deste modo outro dos problemas que se põem e que permitirá a manutenção da segurança da rede.

Outro desafio interessante que se põe no desenvolvimento do portal é a inclusão de ferramentas de formação, isto é, uma zona de e-learning. Esta formação poderá ser científica ou técnica. Prevê-se que sejam incluídos temas como o tratamento e gestão da informação recolhida nos vários destinos turísticos, a gestão do desempenho no sector de turismo ou o manual de boas práticas. Em qualquer dos casos, o processo de formação deverá incluir questionários de auto-avaliação, e de acordo com os resultados um aconselhamento ou chamadas de atenção para determinados factores.

Deverão ainda ser disponibilizada página de alojamento para os destinos turísticos, prontos a ser preenchida com informação local enquanto conservam um aspecto comum. Estas páginas devem estar preparadas para receber imagens e vídeos.

$\mathrm{Na}$ fase prévia de análise bem como as fases de desenvolvimento e teste da aplicação será necessário considerar o envolvimento de uma equipa que integre não só especialistas em informática como também alguns representantes das organizações do sector e consultores de gestão de desempenho. Será também necessária uma máquina para o desenvolvimento do sistema, de características semelhantes à que suportará a exploração do sistema.

Nas fases de exploração e manutenção, serão necessários um técnico superior de informática, e um computador / servidor. De notar que a obsolescência programada dos equipamentos informáticos recomenda que se considere a actualização dos equipamentos em prazos não superiores há 15 meses.

Considerando que a utilidade de uma rede de partilha de informação varia exponencialmente com o número de utilizadores, as necessidades de armazenamento de informação e interligação dos componentes também deve ser periodicamente revista.

Enc. Bibli: R. Eletr. Bibliotecon. Ci. Inf., Florianópolis, n. esp., 2º sem. 2008 


\subsection{Desenvolvimento do Portal Web DESTUR}

No âmbito do desenvolvimento da rede de partilha de informação turística, foi criado na Universidade do Algarve, um sistema piloto com objectivo de suportar e dinamizar a monitorização da qualidade de destinos turísticos. Este portal, denominado DESTUR (derivado de "DEStinos TURísticos"), constitui uma primeira abordagem à segunda etapa na concepção de uma futura rede de informação turística, que poderá ser expandida tanto a nível nacional como internacional.

O sistema desenvolvido é constituído por um portal web e uma base de dados com informação do sector turístico da região do Algarve, tendo em conta indicadores de qualidade ambiental.

Os destinos turísticos são monitorizados periodicamente, segundo determinados indicadores de qualidade implementados por entidades devidamente autorizadas. Cada indicador tem associado um determinado número de parâmetros ou critérios de avaliação. Os valores de monitorização obtidos são inseridos no sistema através da interface do portal web. Os pesos dos parâmetros ou critérios no cálculo final da qualidade do destino são determinados por investigadores do sector turístico habilitados para o efeito.

Esta ferramenta oferece um meio que facilita o processo de monitorização da qualidade turística, levado a cabo pelos diversos intervenientes do sector, fomentado sinergias interorganizacionais. Assim, contribui-se para o desenvolvimento económico do sector turístico, com uma especial focalização na qualidade ambiental, tão importante nos dias que correm.

Desta forma, o DESTUR visa apresentar aos utilizadores (visitantes, entidades de monitorização e investigadores) os resultados do desempenho de qualidade do destino turístico de uma forma clara e agradável, satisfazendo simultaneamente as necessidades dos turistas e das organizações intervenientes.

\subsection{1 Áreas de acesso ao portal web}

No que concerne à segurança da informação, são tidos em conta os aspectos de confidencialidade, integridade e disponibilidade. Assim, o portal é composto por diferentes áreas de acesso com diferentes privilégios, como mostra a Figura 3.

Cada uma destas áreas apresenta um conjunto de informações e funcionalidades, de acordo com as necessidades dos utilizadores. A cada utilizador do portal é associado um conjunto de permissões de acesso aquando do seu registo no site. Autenticação e gestão de acesso são cruciais para a segurança do sistema, ajudando a aumentar a confiança dos utilizadores no produto.

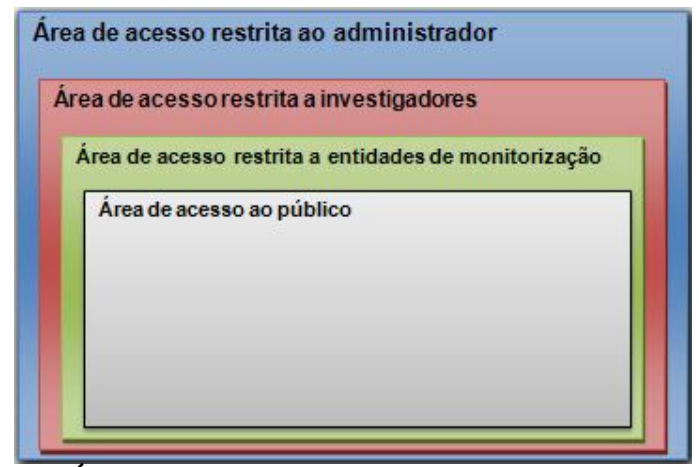

Figura 3 - Áreas de acesso público e restrito do portal web

\subsection{2 Área de acesso ao público}

A área de acesso público diz respeito a todas as páginas que os visitantes do portal podem aceder sem autenticação. Esta área é destinada aos utilizadores finais não registados, que pretendem obter no portal, informação sobre o sector turístico. 
A página de "rosto" do portal permite consultar informação detalhada acerca dos destinos turísticos, das entidades de monitorização, dos indicadores de qualidade utilizados, e dos desempenhos de qualidade dos destinos turísticos obtidos. Esta página inicial contém um formulário de autenticação que permite aos utilizadores registados no portal (investigadores ou entidades de monitorização) aceder às suas correspondentes áreas reservadas.

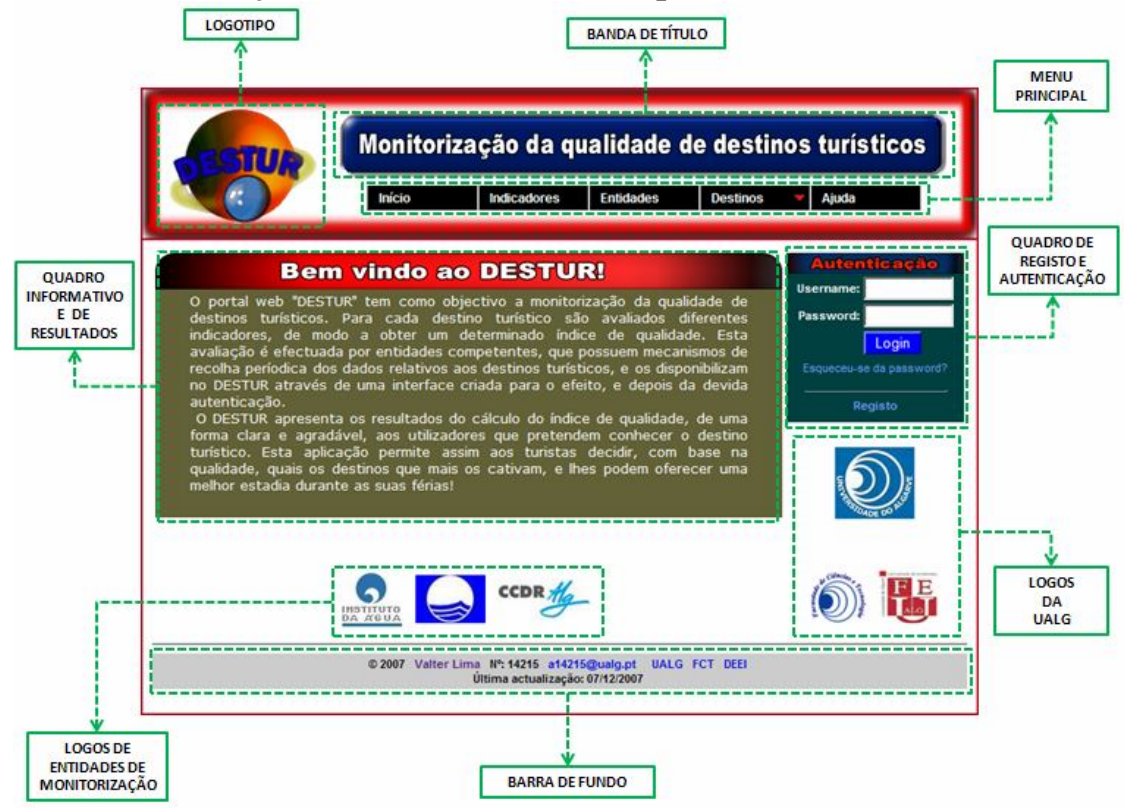

Figura 4 - Página inicial do portal web DESTUR

\subsection{3 Área de acesso restrito a entidades de monitorização}

Nesta secção, as entidades de monitorização têm acesso a formulários que lhes permite introduzirem dados de monitorização dos destinos, recolhidos periodicamente. As entidades de monitorização podem ainda transferir para o sistema, ficheiros com informação de monitorização ou outros documentos de interesse relevante. Podem alterar os dados do perfil da entidade, e consultar toda a informação disponível no sistema sobres os indicadores de qualidade e destinos turísticos.

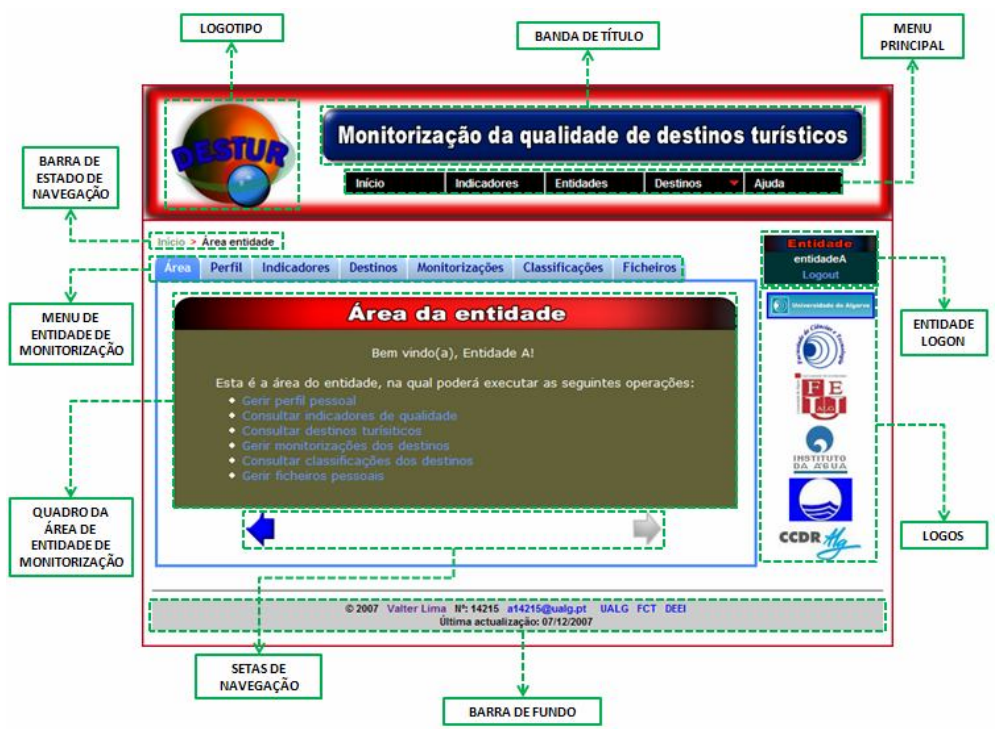

Figura 5 - Área de acesso de entidades de monitorização 
4.4.4 Área de acesso restrito a investigadores do sector turístico

Os investigadores têm a capacidade de realizar todo o tipo de consultas e operações enumeradas nas áreas de acesso anteriores. Esta secção possui as seguintes funcionalidades adicionais:

- Gerir os indicadores de qualidade e respectivos parâmetros/critérios e tipos de classificação associados;

- Gerir toda a informação relacionada com os destinos turísticos;

- Gerir a informação de monitorização de qualidade dos destinos podendo alterar os pesos dos valores no cálculo final da classificação do destino.

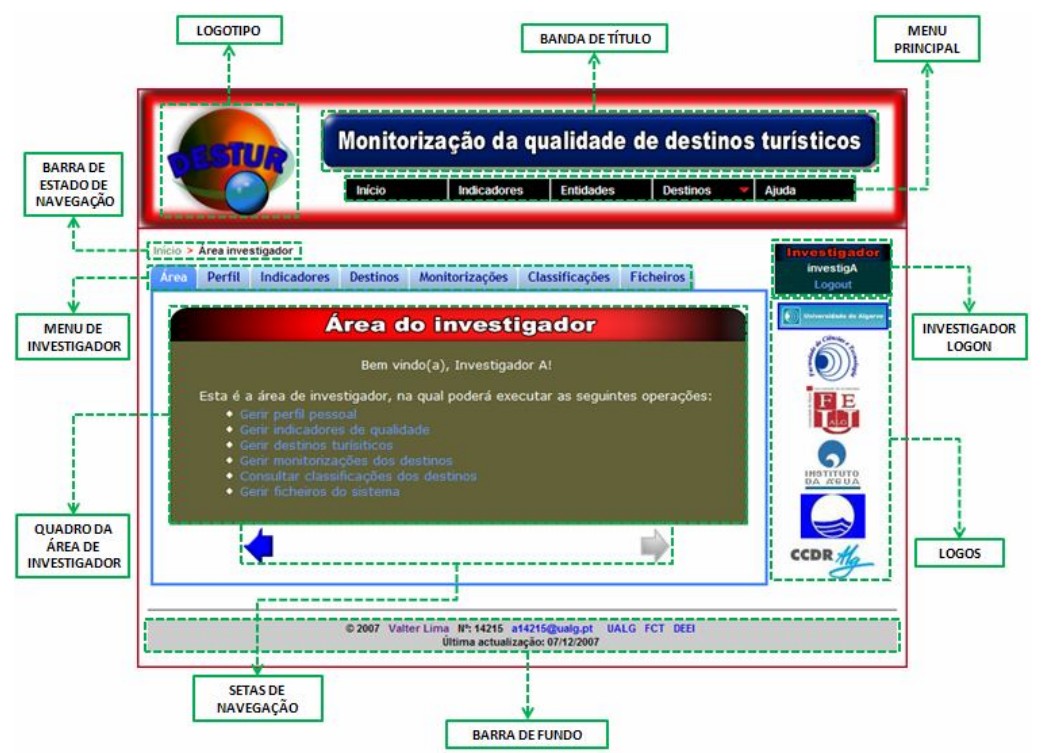

Figura 6 - Área de acesso de investigadores

4.4.5 Área de acesso restrito ao administrador do portal

O administrador do portal é responsável pelo regular funcionamento do mesmo, gerindo todos os registos dos utilizadores no portal.

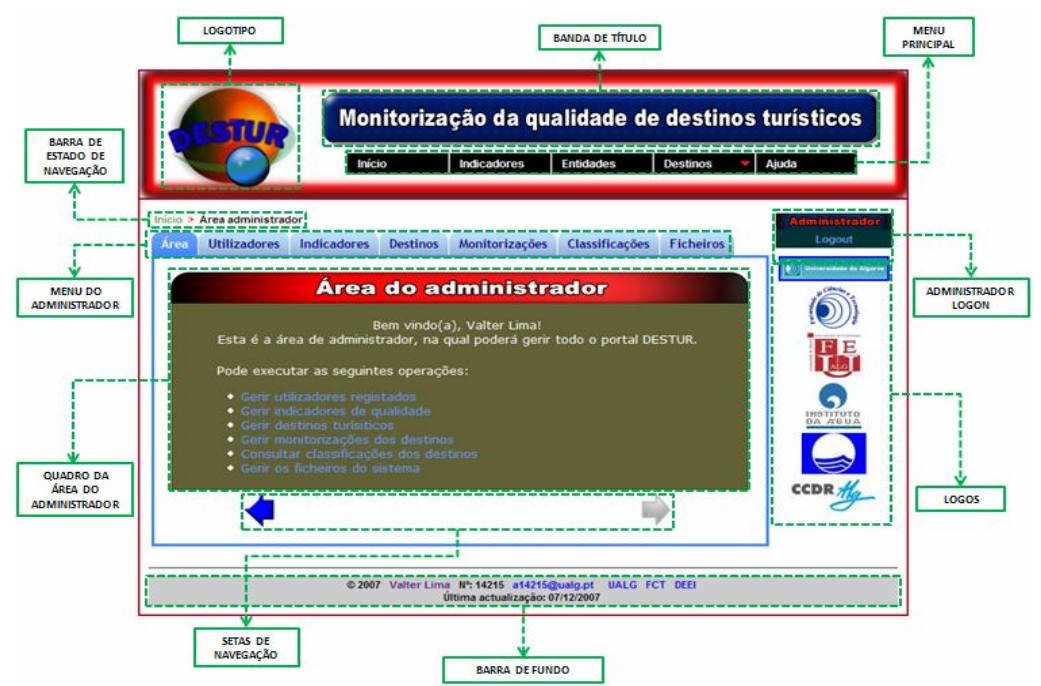

Figura 7 - Área de acesso do administrador 


\section{COMENTÁRIOS FINAIS}

Para a gestão de desempenho no sector turístico em geral e, em particular, quando aplicada a destinos turísticos emergentes, em que a cooperação empresarial é informal pelas dificuldades criadas pela dispersão geográfica ou falta de infra-estruturas tecnológicas e organizacionais, é conveniente o estabelecimento de uma rede de partilha de informação. Tal rede tem como objectivo principal ajudar as partes envolvidas a melhorar o seu desempenho e partilhar o conhecimento de boas práticas.

As redes de partilha de informação no sector turístico, suportadas por TICs, podem ser encaradas de diversas formas: do ponto de vista da estrutura física, consistem na utilização de computadores ligados à Internet, que fazem uso de uma ou mais aplicações, colaborativas ou distribuídas; do ponto de vista das organizações, apoiam processos informais de colaboração e comunicação diferida; quanto ao desempenho dos destinos turísticos, oferecem serviços de gestão de conhecimentos e de monitorização pela aplicação dos instrumentos de diagnóstico de competitividade, sustentabilidade e qualidade.

A integração das tecnologias de informação na constituição da rede visa a partilha de conhecimentos e a formação de boas parcerias. Factores de sucesso para alcançar os objectivos pretendidos serão: a liderança (através do empenho das entidades competentes); o envolvimento dos sectores público e privado e das comunidades; a capacidade de realizar projectos; um planeamento e execução faseados (começando com projectos de pequena dimensão) e, por último, o sistema de benchmarking que vai interligar os destinos turísticos dos países de expressão portuguesa.

No portal web DESTUR criado, é possível consultar informação de qualidade ambiental do sector turístico, de uma forma consistente, gráfica e apelativa. A sua interface é de fácil utilização, permitindo o acesso a diferentes tipos de agentes envolvidos na monitorização dos destinos turísticos, depois de devida autenticação.

Nesta primeira abordagem ao projecto de constituição de uma rede de partilha de informação turística foi tratada informação do sector turístico da região do Algarve na vertente ambiental. Contudo, a ferramenta web está preparada para receber novos destinos turísticos e novos tipos de vectores de monitorização da qualidade.

\section{REFERÊNCIAS}

AFFIT. Information Network for the Sustainable Development of tourism Destinations in Europe. Agence Française de l'Ingénierie Touristique, 2001.

BUHALIS, D. Marketing the competitive destination of the future. Tourism Management, v.21, p. 97-116, 2000.

COMISSÃO PARA A POLÍTICA DE INFORMÁTICA, Estratégia de Implementação da Política de Informática, www.infopol.gov.mz, (ISBN) Registo N.o 3011/INLD/2002, Maputo ( Moçambique): Ed. Salomao Manhiça, 2002.

COULOURIS, George; DOLlIMORE, Jean; KINDBERG, Tim. Distributed Systems Concepts and Design. 3 Ed., Adison Wesley, Pearson Education, ISBN: 0201-61918-0, 2001.

UNIÃO EUROPEIA, eEurope 2002 Action Plan, Brussels, disponível em http://europa.eu.int/information society/eeurope/2002/action plan/pdf/actionplan en.pdf, 2000.

DAVIDSON, R.; MAITLAND, R. Tourism Destinations, London, Hodder \& Stoughton Educational, 1997.

EFQM, Eight Essentials of Excellence, European Foundation for Quality Management, Brussels, 1999. 
JEONG, S.; GRETZEL, U.; FESENMAIER, D. R. eReady: A Diagnostic Tool of Internet Readiness for Tourism Organizations in Proceedings The Annual Conference, Travel and Tourism Research Association, Arlington, 2002.

KLEIN, R. EU activities to improve the quality of European tourist products in Workshop on Quality in Tourism: from Patterns to indicators, Faro, Universidade do Algarve, 2000.

LEONI, P. La città ospitale in International Conference From Destination to Destination Marketing and Management, Venice, 1999.

MANENTE, M.; FURLAN, M. C. Quality in the Macroeconomics System of Tourism, Revue de Tourisme, v. 2, p. 17-28, 1998.

MCHUGH, P.; MERLI, G.; WHEELER III, W. A. Beyond Business Process Reengineering - Towards the Holonic Entreprise, Chichester, John Wiley \& Sons, 1995.

MENDES, Júlio A Gestão da Qualidade dos Destinos Turísticos. O caso português. Faro (Portugal), Faculdade de Ciências Económicas e Empresariais, Universidade do Algarve, Tese de Doutoramento, 500 p., 2004.

NEPAD. Nova Parceria para o Desenvolvimento de África. Abuja, Nigéria, Outubro, disponível em http://www.inpeco.pt/padc/index padc.html, 2001.

O'NEILL, M. A.; WATSON, H.; MCKENNA, E. Service Quality in the Northern Ireland Hospitality Industry. Managing Service Quality, v. 4, 3, p. 36-40, 1994.

RITCHIE, J.R.B.; CROUCH, G. I. Roles and contributions to destination competitiveness, Proceedings in the 47rd Congress of the Association International d'Experts Scientifiques du Tourisme, Cha-Am, Thailand, p. 117-139, 1997.

SILVA, J. A.; MENDES, J.; GUERREIRO, M. M A Qualidade dos Destinos Turísticos: dos Modelos aos Indicadores, Revista Portuguesa de Gestão, v. 3, 1, p. 65-81, 2001.

XIANG, P.; GRETZEL, U.; WANG, R.; FESENMAIER, D. R. Designing B2B Communities for the Tourism Industry: A Case Study of the Illinois Tourism Network (ITN), in Proceedings of The Annual Conference, Travel and Tourism Research Association, Arlington, 2002.

\begin{abstract}
Global and efficient communication has always been a goal to expanding touristic destinations in order to potentiate the growth of the sector and the sustainable development of the regions concerned. With the emergence of the new information technologies, the creation of networks for information sharing became a reality. This facilitated the implementation of benchmarking actions and programs between touristic destinations involved in cooperation projects. The Internet development, as an inexpensive infrastructure, allowed breaking many access barriers faced by many touristic destinations, due to the lack of investment funds in these areas. The inherent cost of design, installation and maintenance of networked computer systems are currently a fraction of the initial implementation cost of a traditional system, even allowing for the standardization of all the technology applied. The article exposes the problematical issues concerning the creation of networks for information sharing and proposes a model for the development of a distributed information system as the support infrastructure to such a network. Thus, the organized exploitation of a decentralized information flow allows the creation of synergies amongst the agents involved and, at the same time, the maximization of the development of the emerging touristic destinations. Such $\mathrm{s}$ network towards the sustainable development of the touristic destinations of Portuguese speaking countries of enables the development of processes of continuous enhancement of the global performance, processes that are oriented to the pursuit of competitivity, sustainability and quality of touristic products.
\end{abstract}

Enc. Bibli: R. Eletr. Bibliotecon. Ci. Inf., Florianópolis, n. esp., 2º sem. 2008 
Key words: Touristic destinations; Performance Management; Information Systems; Distributed Systems.

Originais recebidos em: 30/09/2008

Texto aprovado em: 06/11/2008 